\title{
Enseñar fraseología: consideraciones sobre la fraseodidáctica del español
}

\author{
Francisco NúÑEZ-ROMÁN \\ Universidad de Sevilla \\ Departamento de Didáctica de la Lengua y la Literatura y Filologías Integradas \\ fnroman@us.es
}

Recibido: 30 de enero de 2015

Aceptado: 16 de marzo de 2015

\section{RESUMEN}

El objetivo de este trabajo es analizar la presencia de la fraseología en los niveles de enseñanza obligatoria y proponer una serie de actividades cuyo objetivo sea desarrollar la competencia fraseológica de hablantes nativos de español. Tras mostrar la importancia de la fraseología como parte fundamental del caudal lingüístico de un hablante nativo y defender la existencia de la competencia fraseológica también en lengua materna, se examina la presencia de la fraseología en las diferentes vertientes de la competencia en comunicación lingüística del actual currículo: pragmática, lingüística, sociolingüística y literaria. Se indica, además, el importante papel que puede jugar al abordar determinados contenidos desde una perspectiva transversal (fraseología y cultura). Para finalizar, se hacen algunas propuestas sobre cómo debe presentarse la fraseología en lengua materna y se presentan diferentes actividades según el nivel de enseñanza.

Palabras clave: fraseología, español, didáctica del léxico, competencia léxica.

\section{Teaching phraseology: considerations on Spanish Phraseodidactics}

\begin{abstract}
The aim of this paper is to analyze the presence of Phraseology in primary and secondary education levels and to propose a series of activities intended to develop the phraseological competence of native Spanish speakers. After demonstrating the importance of Phraseology as a fundamental part of the linguistic output of a native speaker and defending the existence of this phraseological competence also in L1, we analyze the relationships between Phraseology and other linguistic and non-linguistic competences included in the curriculum of primary and secondary education, such as the lexical competence, the sociolinguistic competence and the pragmatic competence. It is also showed the important role it can play in focusing specific subjects from a transversal perspective (Phraseology and culture). Finally, we make some remarks on how Phraseology should be taught in mother tongue and we propose different activities according to the level of education.
\end{abstract}

Key words: phraseology, Spanish language, lexical didactics, lexical competence. 


\section{Enseigner la phraséologie: considérations sur la phraséodidactique de l'espagnol}

\section{RÉSUMÉ}

Ce travail analyse la présence de la Phraséologie en l'enseignement obligatoire et propose une série d'activités visant à développer la compétence phraséologique en espagnol comme langue maternelle. Après avoir montré l'importance de la Phraséologie comme une partie fondamentale du débit linguistique d'un locuteur natif, et avoir défendu l'existence de cette compétence phraséologique aussi dans la L1, on examine la présence de la Phraséologie dans le programme de l'école primaire et secondaire : la compétence lexicale, la compétence sociolinguistique et la compétence pragmatique. On montre aussi le rôle essentiel qu'elle peut jouer dans le traitement de certains contenus d'une perspective transversale (Phraséologie et culture). Finalement, on fait quelques observations sur comment la Phraséologie doit être présentée en langue maternelle et on propose de diverses activités en fonction du niveau éducatif.

Mot-clés: phraséologie, espagnol, didactique du lexique, compétence lexicale.

SUMARIO: 1. Introducción; 2. ¿Para qué sirve enseñar la fraseología?; 2.1. La fraseología como instrumento para desarrollar la competencia en comunicación lingüística; $2.2 \mathrm{La}$ fraseología como puente hacia el lenguaje figurado; 2.3. La fraseología como puente hacia otras competencias; 3. Cómo debe presentarse la fraseología en lengua materna; 4. Conclusiones; 5. Bibliografía.

\section{INTRODUCCIÓN}

La fraseología se ha afirmado en los últimos años como un componente fundamental de la lingüística, y de ser considerada un aspecto marginal del lenguaje ha pasado a convertirse en un fructífero campo de estudio con múltiples y productivas facetas. Una de las ramas que ha vivido un rápido desarrollo en el ámbito de la fraseología aplicada ha sido la fraseodidáctica. Esta evolución ha sido aprovechada sobre todo en el ámbito de la enseñanza de lenguas extranjeras, produciendo un interesante número de publicaciones y métodos destinados a la enseñanza de la fraseología para estudiantes alófonos, pero no ha tenido apenas reflejo en la enseñanza de la lengua materna.

Este vacío coincide con la ausencia casi total del hecho fraseológico en los niveles iniciales y medios de enseñanza de la lengua materna y su escasa presencia en el nivel universitario. Como señala Martínez Marín (1999, 99), las unidades fraseológicas (UF) son "insuficientemente atendidas $-\mathrm{y}$ eso cuando lo son- en la enseñanza del castellano, aunque tienen una gran importancia en su estructura y funcionamiento, como ha revelado la investigación”. En este sentido, González Rey $(2004,119)$ cree que esta ausencia se debe a varios factores, entre los que enumera la consideración de la fraseología como un hecho propio de la cultura popular y por lo tanto secundario en el desarrollo de la competencia escrita; la falta de preparación de los docentes y la escasez de recursos pedagógicos; y, por último, el 
hecho de que se trate de un campo de estudio íntimamente ligado a la investigación universitaria, único ámbito en el que se han producido avances palpables en fraseodidáctica. Dada esta situación, esta autora pide potenciar el esfuerzo allí donde el vacío es mayor, esto es, en la fraseodidáctica de las lenguas maternas, y en especial en los niveles de primaria y secundaria. González Rey $(2004,120)$ considera que "o primeiro paso que debemos dar para mellora-las estratexias de aprendizaxe das unidades fraseolóxicas empeza pola propia convicción de que se trata dun aspecto lingüístico e cultural digno de ensinar na propia lingua materna".

Lamentablemente, este paso no se ha dado aún de una manera definitiva, como demuestran los nuevos currículos de Educación Primaria y Secundaria en los que la fraseología aparece de manera circunstancial como parte del vocabulario (R.D. 126/2014) o como un contenido exclusivo de la lengua extranjera (R.D. 1105/2014). Una mayor atención a la fraseología en lengua materna supondrá una mayor disponibilidad de recursos, y por lo tanto, una mayor competencia en comunicación lingüística, superando las fronteras del dominio léxico y convirtiéndose también en un elemento importante en la reflexión sobre el conocimiento de la lengua, sin olvidar el importante papel que este tipo de estructuras juega en el desarrollo de las destrezas discursivas.

\section{2. ¿PARA QUÉ SIRVE ENSEÑAR LA FRASEOLOGÍA? \\ 2.1 La fraseología como instrumento para desarrollar la competencia en comunicación lingüística}

Se podría argumentar, en contra de una mayor atención al hecho fraseológico en los ciclos formativos obligatorios, que la fraseología, al igual que se aprende el vocabulario general, es adquirida de manera natural por parte de un hablante nativo "a partir de la repetición y retención de las formas y de los significados de dichas estructuras" (Forment Fernández, 1998, 341). Los hablantes nativos disponen de un amplio repertorio de fraseologismos, adquiridos a través del uso, que conforman lo que Solano Rodríguez (2007) denomina "competencia fraseológica", que debería ser añadida al resto de habilidades lingüísticas ${ }^{1}$. Esta competencia fraseológica estaría apoyada en una "conciencia fraseológica" (Solano Rodríguez 2007), es decir, un conocimiento inconsciente por parte del hablante de la existencia de este tipo de estructuras, de las que hace un uso correcto aún cuando en muchas ocasiones las UF contengan aberraciones sintácticas o semánticas, como en a ojos vista o como los chorros del oro. Que se trate de una competencia específica se observa con claridad en la producción de un hablante nativo, en la que el número de

\footnotetext{
${ }^{1}$ Esta autora reflexiona sobre la "competencia fraseológica" en el ámbito del Marco Común Europeo de Referencia para las Lenguas y la adquisición de una lengua extranjera. No obstante, consideramos que se trata de un concepto interesante que se debe importar a la enseñanza de la lengua materna.
} 
fraseologismos es manifiestamente superior si la comparamos con la producción de un hablante no nativo. Es cierto que, como ha afirmado Ettinger (2008), es posible comunicarse en una lengua sin apenas hacer uso de fraseologismos, como lo hace un aprendiz de L2 hasta bien avanzado el dominio de esta; no obstante, el conocimiento y uso de la fraseología de una lengua supone un notable salto cualitativo y enriquece con numerosos matices el mensaje.

Tradicionalmente, y desde la perspectiva de la didáctica de la lengua, la fraseología ha sido emparentada con el léxico, debido sobre todo a una de sus características: su significado unitario. En efecto, amén de su carácter poliléxico (una unidad fraseológica está compuesta por al menos dos palabras), cualquier unidad fraseológica se caracteriza por presentar un significado conjunto $\mathrm{y}$, en la mayoría de los casos, este significado no es deducible a partir del significado individual de sus componentes, presentando un mayor o menor grado de idiomaticidad. Esta característica hace que las unidades fraseológicas sean percibidas por los hablantes como un único bloque de significado, y que, por lo tanto, sean almacenadas como un elemento más del léxico. En este sentido, Prado Aragonés (1999, 157), al relacionar los objetivos que hay que alcanzar en el desarrollo de la competencia léxica en Educación Primaria, indica que el alumno deberá reflexionar sobre "las múltiples posibilidades creativas y expresivas que la lengua ofrece con el conocimiento de modismos, refranes y frases hechas".

Si analizamos los componentes de una UF, podemos observar que la fraseología es también reducto de una parte del léxico que únicamente podemos encontrar dentro de una unidad fraseológica. Hablamos de las denominadas palabras diacríticas, es decir, palabras que no se usan fuera de una construcción fraseológica. Son ejemplos de unidades fraseológicas formadas por palabras diacríticas a troche $y$ moche, a tocateja, por arte de birlibirloque, en cuclillas o en un santiamén; en estos casos, las palabras troche, moche, tocateja, birlibirloque, cuclillas o santiamén no pueden usarse de manera independiente fuera de la unidad fraseológica que constituyen. Aunque se trata de uno de los obstáculos más importantes en el aprendizaje de UF en estudiantes de L2, en el caso de estudiantes de L1 supone una interesante ocasión para reflexionar sobre el origen y la evolución del léxico de su lengua.

La fraseología es útil también para el desarrollo de la comunicación oral, puesto que, desde el punto de vista de la producción, es un componente sustancial en el proceso de ampliación del vocabulario. Las locuciones, además, se entienden como uno de los recursos básicos del texto oral, necesario para la comprensión global del mismo (R.D. 126/2014), por lo que su conocimiento y uso adecuado mejora la competencia comunicativa de los alumnos.

El uso del diccionario es una estrategia básica para el desarrollo de la competencia léxica en Educación Primaria, y la fraseología suele trabajarse casi de manera exclusiva en estrecha relación con el diccionario escolar. De hecho, Prado Aragonés (2001), al examinar la selección y el uso del diccionario como recurso 
para el desarrollo de la competencia léxica, indica, entre otros aspectos que se deben tener en cuenta, que estos incluyan "modismos y frases hechas y también el sentido figurado, así como los distintos niveles de uso, sobre todo si son tecnicismos" (Prado Aragonés, 2001, 212), lo que permitirá al alumno conocer el significado de estas construcciones de nuestra lengua. Sin embargo, hay que señalar que los diccionarios, tanto los generales como en especial los escolares, presentan unas notables deficiencias en la recopilación y presentación de la fraseología, como recoge Azorín Fernández (2000, 87):

la fraseología, especialmente las combinaciones pluriverbales de carácter idiomático [...] parece ser uno de los aspectos de la lengua materna (o extranjera) que, por sus implicaciones culturales y por las dificultades que presenta de cara a su actualización en el discurso, necesita de una mayor atención por parte del diccionario escolar.

Es fundamental, por lo tanto, que el profesorado conozca los diversos repertorios fraseológicos disponibles, así como su organización interna, para sacar el máximo provecho de los mismos. En este sentido, es necesario un mayor esfuerzo investigador que permita conocer los conocimientos fraseológicos de los alumnos a través de la elaboración de fraseologías disponibles, equivalentes a los actuales estudios de léxico disponible, que nos darían una visión de conjunto fundamental para poder focalizar la atención en aquellas áreas temáticas más débiles y elaborar materiales didácticos más eficaces.

Martínez Marín (1998; 1999) destaca la importancia del hecho fraseológico en el desarrollo de las destrezas discursivas. En este ámbito, la cohesión textual es uno de los aprendizajes fundamentales en el desarrollo de la comunicación escrita. La función de las unidades fraseológicas como conectores textuales es primordial, en especial en las locuciones conjuntivas (con tal de que, puesto que, a fin de que, siempre que, a condición de que, etc.), por lo que conocer su uso mejorará el bloque de comunicación escrita. Las destrezas discursivas adquieren una mayor importancia en Educación Secundaria, ya que el análisis de diferentes tipologías textuales es una parte importante del currículum. Nos referimos, por ejemplo, a textos de tipo periodístico, jurídico o publicitario, cuyas características se examinan y se tratan de reproducir en el aula. La función de la fraseología en estos textos es fundamental, ya que sirve para formalizar un tipo de lenguaje con unas finalidades y unas estructuras muy concretas. Determinar con exactitud el repertorio fraseológico ligado a cada tipología textual se convierte en un factor indispensable para conocer mejor las UF y es a su vez una herramienta muy útil para el alumno desde el punto de vista de la producción escrita.

Por último, organizar un discurso conforme a la situación y las necesidades comunicativas con los recursos lingüísticos pertinentes forma parte de los estándares de aprendizaje en Educación Primaria (R.D. 126/2014). Sin embargo, los factores pragmáticos y sociolingüísticos suelen quedar en un segundo plano, incluso 
en la enseñanza de UF a estudiantes extranjeros. Las relaciones situacionales que se dan entre formas simples como castigar y unidades fraseológicas sinónimas como meter un puro son fundamentales para mejorar la competencia sociolingüística. Las unidades fraseológicas, especialmente las locuciones verbales y adjetivales, suelen estar marcadas sociolingüísticamente, aunque estas diferencias, como señala Sánchez Muñoz (2009), no suelen estar recogidas en los diccionarios con toda la precisión necesaria. Las diferencias entre pasarlo en grande y divertirse o entre de calle y sobradamente están marcadas por factores diafásicos o diastráticos que los alumnos deben conocer para saber emplearlas en los contextos y situaciones adecuadas.

\subsection{La fraseología como puente hacia el lenguaje figurado}

Nuestra visión del mundo se organiza a través de uno de los procesos cognitivos más productivos desde el punto de vista lingüístico, la metáfora, y este proceso se refleja claramente en la organización semántica y temática de las unidades fraseológicas. Gracias a los procesos metafóricos somos capaces de entender y presentar un determinado concepto por medio de otro que nos resulta más familiar o más conocido. Todos entendemos de manera correcta expresiones del tipo tomar el pelo o tela marinera aunque no estemos hablando de peluquería ni de tipos de tejidos. Este proceso cognitivo está en la base de numerosas expresiones fraseológicas que, en muchas ocasiones, resultan difíciles de entender si no se filtran a través de los procesos metafóricos. Esta dificultad no afecta únicamente a los hablantes no nativos que aprenden una segunda lengua, sino también a los hablantes nativos cuya experiencia del mundo no es lo suficientemente amplia, como es el caso del alumnado de Educación Primaria (y en menor medida, el alumnado de Educación Secundaria). La comprensión del lenguaje figurado, por otro lado, es uno de los objetivos de los bloques dedicados a la lectura y a la educación literaria (R.D. 126/2014).

En expresiones como estar ciego de amor o empezar una relación se considera el amor como una enfermedad o un viaje, respectivamente, y expresiones del tipo dar un paso adelante entiende el desarrollo de una acción desde la perspectiva del movimiento. Como sostiene Carmen Navarro, "la competencia comunicativa requiere la metáfora para captar esos sentidos figurados, ironías y el variado repertorio de connotaciones que tienen los fraseologismos" (Navarro, 2003, 103).

Presentar las unidades fraseológicas agrupadas en torno a un concepto metafórico concreto permite no sólo ampliar la competencia léxica de un alumno, sino también hacer al alumno consciente y partícipe de la manera en la que su mente organiza la realidad. Poner en relación fraseologismos como ir a paso de tortuga, ir a todo gas o navegar viento en popa, que se organizan en torno a la metáfora acción es movimiento y su implicación metafórica 'la velocidad de la acción es la velocidad del movimiento', facilitan el desarrollo cognitivo del alumno ampliando su visión del mundo. 


\subsection{La fraseología como puente hacia otras competencias}

La competencia fraseológica, además, permite desarrollar otras competencias no lingüísticas, como la conciencia y expresiones culturales o las competencias sociales y cívicas. Son numerosas las unidades fraseológicas de difícil comprensión por incluir referencias histórico-culturales desconocidas para el hablante. En este caso, el contexto es determinante para descifrar el significado, como en la expresión armar la de San Quintín, muy extendida y utilizada gracias al contexto de uso a través del cual se aprende, pero cuyo origen, la victoria de Felipe II sobre el monarca francés Francisco I en la ciudad francesa de San Quintín en 1557, es desconocido para la mayoría de hablantes. Otros ejemplos de este tipo son expresiones como discusión bizantina, ser la cenicienta, pasar las de Caín o arder Troya. Muchas expresiones fraseológicas tienen su origen en la literatura nacional o universal o en referencias culturales comunes a varios países, lo que las convierte en punto de unión entre la lengua y la literatura (no dejar títere con cabeza o poderoso caballero es don dinero, cuyos orígenes están en el Quijote de Cervantes o en Quevedo, respectivamente), la filosofía (solo sé que no sé nada), la religión (ojo por ojo y diente por diente, ser más viejo que Matusalem), la historia (más se perdió en Cuba, París bien vale una misa), las matemáticas (elevar algo a la enésima potencia) o las ciencias (estar como el perro y el gato). Además, hay que tener en cuenta la actual pluriculturalidad de las aulas: la presencia de alumnado inmigrante supone un nuevo reto que las UF pueden ayudar a superar, acercando a través de las unidades fraseológicas la realidad histórica y cultural del país de acogida.

\section{CÓMO PODEMOS PRESENTAR LA FRASEOLOGÍA EN LENGUA MATERNA}

Asumiendo la importancia de la fraseología en la lengua estándar y considerando la existencia de la denominada "competencia fraseológica", ¿Cómo debe presentarse la fraseología en lengua materna? ¿Como parte del léxico? ¿Como elementos de la competencia comunicativa y discursiva? ¿Como ejemplos de la competencia cultural? Precisamente, la diversidad de aspectos desde los que se puede enfocar el acercamiento a la fraseología hace de ésta un tipo de contenido lingüístico especialmente flexible y polivalente, adecuado para desarrollar de manera transversal diversas competencias. Las propuestas didácticas basadas en las unidades fraseológicas (UF) de la lengua materna permiten, por lo tanto, abordar diferentes contenidos del currículo, por lo que se rebela como un recurso muy productivo.

Martínez Marín (1999) indica algunos ámbitos de aplicación del fenómeno fraseológico en el aula de lengua española, destacando que cada tipo de fraseologismo se adapta mejor a reforzar determinados aspectos del currículo. Las unidades fraseológicas, según este autor, se prestan a ser tratadas desde perspectivas muy diversas, a causa de su carácter heterogéneo. De este modo, considera que las 
colocaciones (llamadas por él unidades léxicas complejas) son importantes en el estudio de la formación del léxico y en el estudio de los lenguajes específicos. Es posible abordar la fraseología teniendo en cuenta su relación con la sintaxis (por su presencia en la función de adyacente - hombre de armas tomar-o el uso habitual de nexos conjuntivos - a condición de que, con la finalidad de), o bien desde el punto de vista de la modalidad (los modalizadores suelen ser unidades fraseológicas: al fin, menos mal que, gracias a Dios, etc.). Las UF también pueden ser afrontadas desde la perspectiva de la estructura del texto, pues muchos conectores textuales son UF (esto es, dicho de otra manera, en resumidas cuentas, etc.).

Dado que las UF se aprenden como una unidad de significado y que en Educación Primaria es irrelevante un análisis pormenorizado de los diferentes tipos de UF y sus características, creemos que la enseñanza de la fraseología en lengua materna debe compartir las mismas estrategias y actividades propias de la enseñanza del léxico, lo que por otro lado no quiere decir que su aprendizaje se reduzca al mero almacenamiento memorístico. Prado Aragonés (2004) propone las siguientes estrategias para la adquisición del léxico en Educación Primaria:

a. Seleccionar adecuadamente el léxico según las necesidades comunicativas básicas de los alumnos, la frecuencia de uso y los centros de interés habituales;

b. Aprender el nuevo vocabulario a través de situaciones comunicativas reales y contextualizadas;

c. Aumentar la especialización del vocabulario en niveles superiores;

d. Poner énfasis en las relaciones semánticas (sinonimia, antonimia, homonimia) y cognitivas (relaciones conceptuales) que pueda establecer el nuevo vocabulario adquirido;

e. Hacer uso de estrategias y actividades motivadoras y lúdicas, incluyendo actividades de refuerzo que permitan consolidar el vocabulario adquirido y permitan incluir el uso del diccionario en clase.

Estas estrategias nos permiten abordar uno de los aspectos más controvertidos en la enseñanza de las UF, en concreto determinar qué UF hay que enseñar y en qué momento del proceso de aprendizaje hay que enseñarlas. Se trata de una cuestión fundamental en cualquier proceso de enseñanza-aprendizaje, pero que adquiere especial relevancia en el caso de las UF.

Uno de los criterios más usados para determinar la importancia de una UF es su frecuencia de uso. Sin embargo, no contamos aún con un mínimo fraseológico que nos permita presentar las UF por su frecuencia. Del mismo modo, la organización de UF en centros de interés relevantes para el alumno supondría un importante avance en la selección de las UF, pero lamentablemente no hay aún ningún repertorio fraseológico organizado según este criterio.

Las relaciones semánticas y cognitivas entre UF son un instrumento fundamental para enriquecer el vocabulario y ampliar la organización semántica de los alumnos, ya que estimula la creatividad y activa conexiones de significado hasta entonces 
aletargadas. Se trata de uno de los criterios de presentación de UF más productivo, y es muy adecuado tanto en fases iniciales de aprendizaje -al mejorar habilidades como el manejo del diccionario- como en etapas posteriores, donde juega un papel importante la especialización.

Por lo tanto, teniendo en cuenta los objetivos de cada etapa educativa, será necesario presentar en clase el hecho fraseológico de dos maneras diferentes.

En Educación Primaria, en la que es fundamental mejorar y enriquecer la capacidad comunicativa de los alumnos, será de especial utilidad la presentación de las UF agrupadas por temas o por palabras clave. Esto permitirá la creación de mapas conceptuales en los que se presenten las UF que giren en torno a un tema determinado, además de servir como ejercicio de familiarización con el diccionario.

Proponemos a continuación, basándonos en las fases presentadas por Prado Aragonés (2004), una posible secuenciación de actividades para desarrollar la competencia fraseológica.

a. Fase de reconocimiento: en esta primera fase, se señalarán las UF objeto de estudio extraídas de un texto oral o escrito. Los alumnos buscarán en el diccionario su significado y lo anotarán.

b. Fase de fijación: en esta fase, se realizarán diferentes actividades destinadas a la fijación formal de la UF. Se propondrán ejercicios para la manipulación e interiorización de las UF. Entre las actividades que se pueden desarrollar, destacan:

a. Realización de dibujos que expliquen el significado de la UF.

b. Realización de dramatizaciones en las que se haga uso de las UF objeto de estudio.

c. Actividades de tipo lúdico: sopa de letras, crucigramas y autodefinidos, pictionary, etc.

c. Fase de exploración: los alumnos deberán ampliar el conocimiento de la UF a través de las relaciones semánticas o temáticas con otras UF. Los alumnos podrán:

a. Buscar todas las UF que contengan la misma palabra base: echar una mano, con las manos en la masa, mano a mano, etc.

b. A partir de una UF, realizar una búsqueda (en el diccionario o a través de sus propios conocimientos) de UF sinónimas: echar una mano, dar una mano a alguien, echar un cable, prestar ayuda, etc.

c. A partir de una UF, buscar otras UF relacionadas temáticamente: boquita de piñón, tener la nariz como un pimiento, tener cara de pan, poner los ojos como platos, etc. 
d. Fase de explotación: en esta fase, el alumno aprenderá a utilizar las UF aprendidas en contextos de uso adecuados. Para ello,

a. Sustituir en frases o textos más amplios palabras simples por unidades fraseológicas con el mismo significado.

b. Crear frases a partir de una UF dada.

c. Elaborar frases con los significados literales e idiomáticos de algunas UF: darle la vuelta a la tortilla, poner toda la carne en el asador, etc.

e. Fase de refuerzo: las actividades de esta última fase ayudarán a fortalecer los conocimientos adquiridos:

a. Reconstruir unidades fraseológicas a partir de la mezcla de varios fraseologismos ya conocidos: *en un abrir y cerrar de párpados, *con los dedos en la masa, *matar dos lechuzas de un tiro, etc.

b. Encontrar errores en la utilización de fraseologismos: *Esta noche voy a dormir con las manos en la masa, *Me han pillado como un tronco.

En Educación Secundaria, además de continuar el perfeccionamiento de los recursos discursivos del alumno, se pone un mayor énfasis en el conocimiento y la reflexión sobre la propia lengua, así como en el análisis detallado de tipologías textuales más complejas. Teniendo en cuenta esta nueva perspectiva, las UF deben presentarse agrupadas por contextos situacionales, por sus funciones discursivas y por su estructura gramatical. Será útil proponer la extracción de UF de determinadas tipologías textuales, como los textos periodísticos, haciendo ver al alumno la preferencia por las UF frente a las formas simples (hacer público por publicar, dar inicio por iniciar, tomar en consideración por considerar), el uso frecuente de conectores (en tanto que, en otro orden de cosas, etc.) o locuciones adverbiales (al parecer) y preposicionales (en calidad de, por virtud de, en el marco de, etc.), sin olvidar las numerosas colocaciones y locuciones nominales que pueblan este tipo de textos (actos vandálicos, cruce de acusaciones, corporaciones locales, etc.). Algunas actividades útiles para el desarrollo de la competencia fraseológica en secundaria son:

a. Reconocimiento de fraseologismos en un texto dado y búsqueda de su significado.

b. Clasificación funcional: locuciones verbales, nominales, adverbiales, adjetivales, preposicionales, etc.

c. Análisis de sus funciones comunicativas.

d. Empleo en textos de especialidad. 
Como actividad que se puede llevar a cabo durante el curso para el desarrollo de la competencia fraseológica de los alumnos, es especialmente útil la elaboración de un diccionario de fraseología local, mediante la creación de fichas fraseológicas en las que se irán anotando las UF que los alumnos van aprendiendo en clase y las que escuchan en su entorno. Estas fichas fraseológicas, en los primeros niveles de enseñanza, contendrán la UF en su forma canónica, el significado de la UF y un ejemplo de uso propuesto en clase. Las fichas se ordenarán según la palabra clave, que deberá ser seleccionada entre todo el grupo. En niveles superiores, especialmente en secundaria, se puede ampliar la información contenida en estas fichas fraseológicas, incluyéndose el ámbito de uso o las relaciones semánticas (sinonimia, antonimia, etc.).

\section{CONCLUSIONES}

Aunque la fraseología es una parte fundamental de la lengua y ocupa un importante espacio dentro del léxico de todo hablante nativo, su enseñanza en lengua materna es testimonial. El desarrollo de la competencia fraseológica, apoyada en la existencia de una conciencia fraseológica ya presente en cada hablante, supone una mejora de la competencia lingüística general del alumno, al ofrecerle nuevos instrumentos expresivos y favorecer una reflexión metalingüística sobre el propio sistema de la lengua.

La competencia fraseológica, además, permitirá al alumno desarrollar de una manera más eficaz algunas de las competencias presentes en los currículos de Educación Primaria y Secundaria. De este modo, la competencia fraseológica:

- mejorará, de manera general, la competencia léxica, al ampliar el vocabulario del alumno;

- permitirá adentrarse en la historia de la lengua, a través de la explicación de las palabras diacríticas presentes en muchos fraseologismos;

- favorecerá el desarrollo y la comprensión del lenguaje metafórico del alumno, sobre el que se basan muchas unidades fraseológicas;

- aumentará la calidad de determinadas tipologías textuales en las que las unidades fraseológicas realizan una labor fundamental desde el punto de vista de la cohesión textual y del uso de determinadas fórmulas expresivas propias (lenguaje periodístico, lenguaje técnico-jurídico, etc.);

- instará a la reflexión sobre aspectos sociolingüísticos del lenguaje, al mostrar las diferencias entre unidades fraseológicas con el mismo significado pero pertenecientes a distintas variedades de la lengua;

- ayudará a desarrollar la conciencia y expresiones culturales y las competencias sociales y cívicas mediante la explicación del origen de muchas de las expresiones fraseológicas basadas en hechos históricos o tradiciones. 
Para ello, es necesario un mayor esfuerzo investigador que nos permita conocer el frásico de los alumnos según su nivel de enseñanza, para poder elaborar los materiales adecuados a las distintas necesidades educativas en Primaria y Secundaria, así como proponer una secuenciación de los contenidos fraseológicos en estrecha relación con el resto de contenidos de cada nivel educativo.

La secuencia propuesta para el desarrollo de la competencia fraseológica de los alumnos, basada en la propuesta de Prado Aragonés (2004) para el desarrollo de la competencia léxica en Primaria, supone cinco fases de actuación (reconocimiento, fijación, exploración, explotación y refuerzo), que deben llevar al alumno a la ampliación de su frásico. Estas actividades deben realizarse en el marco de una propuesta globalizada de contenidos en Educación Primaria, mientras que en Educación Secundaria es posible trabajar de manera específica la competencia fraseológica.

Que pueda darse una mayor presencia de la fraseología en la clase de lengua española como lengua materna depende de otro factor fundamental destacado por todos los autores que han abordado este asunto: es necesaria la formación del profesorado en este campo, pues se trata de un ámbito de la lingüística de reciente desarrollo y aún poco conocido en la formación del profesorado. Por lo tanto, estas nuevas vías solo estarán disponibles y serán fructíferas cuando pongamos a disposición del profesorado en primer lugar los conocimientos que les permitan reconocer y poner en valor estas estructuras, y en segundo lugar, cuando a partir de estos conocimientos, se elabore un material didáctico específico que favorezca el desarrollo de la competencia fraseológica en los alumnos.

\section{BIBLIOGRAFÍA}

ALVAR EZQUeRrA, Manuel (2003): La enseñanza del léxico y el uso del diccionario, Madrid, Arco Libros.

AZORÍN FERNÁNDEZ, Dolores (2000): “¿Para qué usan el diccionario los escolares? Reflexiones a propósito de una encuesta", en Tendencias en la investigación lexicográfica del español: El diccionario como objeto de estudio lingüistico y didáctico. Actas del Congreso celebrado en la Universidad de Huelva del 25 al 27 de noviembre de 1998, RUHSTALler, S. y J. PRADO ARAGONÉS (eds.), Huelva, Universidad de Huelva, 75-100.

BARBADILlo De LA Fuente, María Teresa (1991): La enseñanza del vocabulario, Madrid, Publicaciones E.U. Pablo Montesinos-Universidad Complutense.

BATTANER ARIAS, María Paz (1994): "La investigación en enseñanza del español como lengua materna: vocabulario y léxico", en Actas del Congreso de la Lengua Española: Sevilla, 7 al 10 octubre, 1992, Madrid, Instituto Cervantes, 417-429.

CASTILlo Carballo, María Auxiliadora (2001-2002): "El universo fraseológico: algunos enfoques", en Revista de Lexicografía, 8, 25-41.

CORPAS PASTOR, Gloria (1996): Manual de fraseología española, Madrid, Gredos. 
ETTiNGER, Steffan (2008): "Alcances e límites da fraseodidáctica. Dez preguntas clave sobre o estado actual da investigación", en Cadernos de Fraseoloxía Galega, 10, 95-127.

FORMENT FERNÁNDEZ, María del Mar (1998): "La didáctica de la fraseología ayer y hoy: del aprendizaje memorístico al agrupamiento en los repertorios de funciones comunicativas", en El español como lengua extranjera: del pasado al futuro. Actas del VIII Congreso Internacional de ASELE, MORENO FERNÁNDEZ, F.; GIL BÜRmanN, M.; AlONSO, K. (eds.), Alcalá de Henares, Universidad de Alcalá de Henares, 339-347.

GARCÍA-PAGE, Mario (1993): “El 'modismo' en la enseñanza del español”, en Analecta Malacitana, 16, 1, 347-363.

GONZÁLEZ REY, María Isabel (2004): “A fraseodidáctica: un eido da fraseoloxía aplicada", en Cadernos de Fraseoloxía Galega, 6, 113-130.

GONZÁLEZ REY, María Isabel (2012): "De la didáctica de la fraseología a la fraseodidáctica", en Paremia, 21, 67-84.

MarTín Vegas, Rosa Ana (2009): Manual de Didáctica de la Lengua y la Literatura, Madrid, Síntesis.

MARTíNEZ MARÍN, Juan (1998): "La fraseología y la enseñanza del español como lengua materna", en La lengua española en el aula. Actas de las III Jornadas sobre la Enseñanza de la Lengua Española, GARCÍA WIEDWMANN, E. J.; A. MOYA CORRAl e I. MONTOYA RAMírez (eds.), Granada, Universidad de Granada, 47-59.

MARTÍNEZ MARÍN, Juan (1999): "Unidades léxicas complejas y unidades fraseológicas. Implicaciones didácticas", en V Jornadas de metodología y didáctica de la lengua española: el neologismo, GonZÁlez CALVO, J. M.; M. L. MonTERo Curiel y J. TERRón GONZÁLEZ (eds.), Cáceres, Universidad de Extremadura. Dpto. de Filología Hispánica-Instituto de Ciencias de la Educación, 97-116.

MORENO RAMOS, Jesús (2004): "Enseñar lengua desde un enfoque léxico", en Glosas didácticas, 11, 162-168.

NAVARRO, Carmen (2003): "Didáctica de las unidades fraseológicas", en Didáctica del léxico y nuevas tecnologías, CALVI, M. V.; F. SAN VICENTE (eds.), Viareggio-Lucca, Mauro Baroni Editore, 99-115.

NúÑez Delgado, María Pilar; Del Moral Barrigüete, Cristina (2010): "Competencia léxica y competencia comunicativa: bases para el diseño de programas didácticos en la educación escolar”, en Lenguaje y Textos, 32, 91-96.

PRADO ARAGONÉS, Josefina (1999): "El léxico y sus implicaciones en la Didáctica de la Lengua", en Seminarios de Lingüística, 3, 145-162.

PRADO ARAGONÉS, Josefina (2001): "El diccionario como recurso para la enseñanza del léxico: estrategias y actividades para su aprovechamiento", en Diccionarios y enseñanza, AYALA, M. C. (coord.), Alcalá de Henares, Universidad de Alcalá-Servicio de Publicaciones, 205-226. 
PRADO ARAgONÉS, Josefina (2004): Didáctica de la lengua y la literatura para educar en el siglo XXI, Madrid, La Muralla.

REAL DECRETO 126/2014, de 28 de febrero, por el que se establece el currículo básico de la Educación Primaria.

REAL DECRETO 1105/2014, de 26 de diciembre, por el que se establece el currículo básico de la Educación Secundaria Obligatoria y del Bachillerato.

SÁNCHEZ MUÑOZ, Trinidad (2009): "Las locuciones en los diccionarios escolares: criterios didácticos", en Investigación lexicográfica para la enseñanza de lenguas, GARCÍA Platero, J.M. y M.A. CASTILlo CARBAllo (eds.), Málaga, Universidad de Málaga, 325-345.

SOlANO RoDRÍGUEZ, María Ángeles (2007): "El papel de la conciencia fraseológica en la enseñanza y aprendizaje de una lengua extranjera", en Les expressions figées en didactique des langues étrangères, GONZÁLEZ REY, I. (ed.), Cortil-Wodon, EME, 201-211. 